\title{
Perancangan Struktur Organisasi dan Visual Display untuk Pencegahan dan Penanggulangan Bencana di Gedung X
}

\section{Organizational Structure and Visual Display Design for Disaster Prevention and Management in Building $X$}

\author{
Arif Suryadi, Winda Halim, Jessica, Yoshiko Naomi Simanjuntak \\ Program Studi Teknik Industri Fakultas Teknik Universitas Kristen Maranatha \\ E-mail: arif.suryadi@eng.maranatha.edu, winda.halim@eng.maranatha.edu, \\ jessicajason06@gmail.com, naomiyoshiko11@gmail.com
}

\begin{abstract}
Abstrak
Suatu gedung yang kurang memiliki visual management yang baik menjadi gedung yang berbahaya bagi penghuninya, apalagi jika terjadi bencana seperti gempa bumi atau kebakaran, karena tidak adanya sistem penanganan keadaan darurat yang memadai. Permasalahan yang selalu ditemui oleh orang yang harus datang ke suatu tempat atau gedung yang baru dan cukup luas adalah menemukan suatu tempat tertentu dengan cukup efektif dan efisien. Penelitian ini dilakukan pada sebuah fasilitas pendidikan di Bandung. Gedung $X$ merupakan gedung yang termasuk dalam kategori gedung tinggi karena memiliki 12 lantai. Fungsi utama dari gedung yang bersangkutan adalah sebagai ruangan untuk melaksanakan proses belajar mengajar. Pada penelitian ini akan dilakukan penelitian kualitatif awal yang berguna untuk mengumpulkan sumber-sumber data, seperti penelitian yang pernah dilakukan dan peraturan perundang-undangan yang dapat digunakan untuk perancangan sistem penanganan keadaan darurat. Berdasarkan hal tersebut maka akan dirancang variabel deliveries dan mengembangkan tahapan dari Struktur Organisasi Pengawasan Prosedur Penanganan Bencana (P3B) yang terdiri dari 3 tahapan yaitu penyusunan work breakdown structure (WBS), penyusunan tugas, dan perancangan struktur organisasi, serta ditambahkan pula dengan perancangan visual display. Sehingga dari penelitian tersebut akan diperoleh usulan sistem awalan yang dapat dikembangkan sesuai kebutuhan dari gedung ini ke depan.
\end{abstract}

Kata kunci : bencana, gedung tinggi, struktur organisasi, WBS

\begin{abstract}
Building that lacks of visual management becomes a dangerous building for its occupants, in the event of a disaster such as an earthquake or fire, due to the absence of an adequate emergency handling system. Problems that is always encountered by people who have to come to a new and large place or building is finding a certain place quite effectively and efficiently. This research was conducted at an educational facility in Bandung. Building $X$ is a building that is included in the high building category because it has 12 floors. The main function of the building is as a classroom to carry out the teaching and learning process. In this research, an initial qualitative research will be carried out which is useful for collecting data sources, such as research that has been conducted and legislation, which can be used for designing an emergency handling system. Based on this, the deliveries variable will be designed and the stages of the Disaster Management Procedure Monitoring Organizational Structure will be designed, which consists of 3 stages, namely the preparation of a work breakdown structure (WBS), preparation of tasks, and designing an organizational structure, beside that there are design for visual display. So that from this research, an initial system will be proposed that can be developed according to the needs of this building in the future.
\end{abstract}

Keywords :disaster, high rise building, organizational structure, WBS 


\section{Pendahuluan}

Gedung X merupakan gedung yang terdiri dari banyak ruangan yang berfungsi sebagai ruang kelas. Gedung ini juga memiliki ruangan atau area yang berfungsi sebagai perpustakaan, kantor, foodcourt, ruang seminar, dan ruangan lainnya. Permasalahan yang selalu ditemui oleh orang-orang yang harus datang ke suatu tempat atau gedung yang baru dan cukup luas adalah menemukan suatu tempat tertentu dengan cukup cepat, apalagi jika gedung tersebut belum memiliki penanda tempat atau visual management yang cukup memadai untuk dapat memberikan informasi tempat dan arah. Selain itu, suatu gedung yang kurang memiliki visual management yang baik menjadi gedung yang berbahaya bagi penghuninya. Bahaya tersebut dapat terjadi jika terjadi bencana seperti gempa bumi atau kebakaran karena belum adanya jalur penanda keadaan darurat. Saat keadaan darurat terjadi orang cenderung untuk merasa panik sehingga walaupun orang tersebut bukan orang baru yang menghuni gedung tersebut, orang akan cenderung kebingungan dan membutuhkan waktu yang cukup lama untuk keluar gedung dan menyelamatkan diri.

Berdasarkan hasil penelitian pendahuluan dari beberapa orang responden ditemukan bahwa walaupun sebagian besar responden (54.5\%) tidak merasa cemas terhadap tidak adanya informasi atau ketidakjelasan informasi tentang prosedur pencegahan dan penanggulangan bencana di Gedung X, namun mereka setuju bahwa informasi tentang jalur evakuasi, prosedur pencegahan, dan penanggulangan bencana belum ada $(63.6 \%)$. Kemungkinan untuk merasa tidak cemas dapat disebabkan karena sebagian responden belum pernah berada di gedung tersebut saat terjadinya sebuah bencana, misalnya gempa. Sedangkan, alasan kecemasan pada sebagian responden lainnya disebabkan karena tidak mengerti dan tidak bisa melakukan apapun saat terjadi bencana.

Berdasarkan pada temuan tersebut akan dilakukan penelitian kualitatif untuk mencari berbagai sumber data dan penelitian yang telah dilakukan sebelumnya terkait sistem pencegahan dan penanggulangan bencana yang dapat memudahkan proses perancangan aplikatif yang akan dilakukan selanjutnya yaitu berupa perancangan secara strategis terkait sistem pencegahan dan penanggulangan bencana.

\section{Tinjauan Pustaka}

Beberapa materi utama yang digunakan sebagai dasar penelitian ini, diuraikan pada sub bab di bawah ini:

\subsection{Work Breakdown Structure (WBS)}

WBS adalah bagan hasil pemecahan pekerjaan ke dalam deliverables sampai ke elemen pekerjaan yang dijabarkan dalam bentuk hirarki. Hirarki dari WBS terdiri dari Project, Deliverable, Subdeliverable, Lowest Subdeliverable, Cost Account, dan yang terakhir adalah Work Package. Hirarki tersebut disusun menggunakan level dimulai dari level 1 sampai level 5 (Larson, 2011).

WBS bisa hubungkan dengan unit organisasi yang bertanggung jawab terhadap pekerjaannya. Hasil dari proses menghubungkan ini berupa Organization Breakdown Structure (OBS). Tujuan pembuatan OBS adalah agar bisa dijadwalkan operasi dan tanggung jawab sehingga bisa dirangkum pengukuran kinerjanya akan seperti apa (Larson, 2011).

\subsection{Matriks Tanggung Jawab}

Matriks tanggung jawab atau disebut juga Responsibility Matrix (RM) adalah sebuah matriks yang berisikan informasi tugas apa saja yang harus dikerjakan oleh masing-masing anggota tim proyek dan siapa saja yang bertanggung jawab atas pekerjaan tersebut (Larson, 2011).

\subsection{Manajemen Resiko}

Secara umum langkah-langkah proses manajemen resiko bisa dilakukan dalam empat langkah, yang terdiri dari Identifikasi Resiko, Pengukuran Resiko, Pengembangan Tanggapan Resiko, dan Pengendalian Tanggapan Resiko (Larson, 2011). 


\subsection{Pencegahan Kecelakaan Kerja}

Pencegahan kecelakaan dapat dilakukan dengan hal-hal berikut yaitu, mengurangi hal-hal yang dirasakan dapat membahayakan seperti penggunaan mesin, cara melakukan pekerjaan, penggunaan material, dan memiliki struktur perencanaan yang baik, kemudian karyawan dibekali alat pengaman diri, dan dibekali pengetahuan atau pelatihan (Olishifski, 1985).

Pencegahan kecelakan-kecelakan di tempat kerja dengan melakukan 12 hal, yaitu peraturan perundangan, standarisasi yang diterapkan, pengawasan terhadap, pelaksanaan agar ketentuan dipenuhi, penelitian teknis, penelitian medis, penelitian psikologis, penelitian deskriptif tentang jenis-jenis kecelakan yang telah terjadi, pendidikan, pelatihan-pelatihan, penggairahan, asuransi, dan usaha keselamatan pada tingkat perusahaan (Suma'mur, 1996).

\subsection{Ketentuan OHSAS 18002:2008}

Perencanaan menghadapi keadaan darurat juga harus memperhatikan kesiagaan sistem tanggap darurat. Adapun elemen-elemen dari sistem ini adalah sebagai berikut: penanggung jawab dalam implementasi program, prosedur-prosedur outside emergency cervices and or regulatory agencies, prosedur pemberitahuan kepada karyawan, penghuni, penyewa dan pengunjung, emergency evacuation procedures dan persyaratan latihan evaluasi, emergency evacuation routes, termasuk di dalamnya primary and alternative routes, prosedur operasional keadaan kritis dan proses sebelum melakukan evakuasi, prosedur akomodasi orang disabilitas, prosedur pelaporan karyawan, kontraktor, dan pengunjung selesai emergency evacuation., tugas khusus emergency response teams, alat komunikasi untuk keadaan darurat, alat komunikasi dan prosedur emergency karyawan, penghuni, penyewa dan pengunjung, prosedur on going facitilies inspection untuk menjamin jalur evakuasi terpelihara dengan baik bebas dari hambatan dan bisa dikenali, prosedur komunikasi dengan media dan masyarakat, dan prosedur review secara periodik (OHSAS 18002:2008).

Proses identifikasi bahaya kebakaran dan bahaya ledakan harus memiliki (OHSAS 18002:2008) yaitu: tinjauan bahaya dilengkapi dengan process safety review, hazard operability analysis, job safety analysis or the fire safety review, peninjauan perubahan pada fasilitas, proses atau peralatan minimum 1 tahun sekali, dengan mempertimbangkan hal-hal, antara lain peralatan listrik, smoking, overheated materials, hot surfaces, open flames, spontaneous ignition, static electricity, storage, handling and processing of materials, fired and unfired pressure vessels, flamable or combustionable liquids and gasses, dan accumulation of dust and lint, selanjutnya pengendalian kebakaran dan ledakan mencakup hal-hal berikut: mengisolasi kegiatan atau area berbahaya, memasang peringatan dini, memasang peralatan penanggulangan bahaya kebakaran, program tanda-tanda penyelamatan keluar gedung, seperti: exit lighting or signs, doors, and passage ways, dan pelatihan prosedur evakuasi dalam keadaan darurat bagi semua personel.

Perawatan peralatan keamanan harus dilakukan secara periodik, yaitu peralatan seperti: fire extuinguishers, hose stations, sprinkler systems control valves, special fire protection systems (such as carbon dioxide or other inert gas systems). Prosedur harus dibuat, dipatuhi dengan pengawasan ketat. Prosedur perawatan harus dilaporkan dan dikomunikasikan kemungkinan kerusakan atau cacat kepada departemen terkait atau pihak asuransi (OHSAS 18002:2008).

Menurut OHSAS (Occupational Health and Safety Assessment Series) 18002:2008, clause 4.4.7. evakuasi yang berhasil dan efisien minimum harus memiliki prinsip-prinsip antara lain: organisasi evakuasi gedung, kebijakan evakuasi dan perencanaannya, pendeteksian dan pelaporan adanya bahaya kebakaran, koordinasi program evakuasi, komunikasi mengenai lalu lintas dan evakuasi, dan inspeksi dan evaluasi.

OHSAS 18002:2008, clause 4.4.7. juga mencatat hal-hal yang harus dimiliki dalam perencanaan evakuasi yaitu garis besar perencanaan organisasi emergensi evakuasi, prioritas termasuk tanggung jawab dan wewenang pengelola gedung dan penghuni, pendeteksian, sistem peringatan darurat, dan prosedur pelaporan mengenai kebakaran dan bahaya lainnya, koordinasi dan pusat pengendali evakuasi keadaan darurat gedung dengan menunjuk tim evakuasi lantai (floor emergency 
evacuation teams). Instruksi rantai komando yang rinci dan dipahami oleh penghuni, sistem komunikasi dua arah untuk mengarahkan kerja dari tim evakuasi yang juga terhubung dengan pusat pengendalian serta personil. Pemadam kebakaran juga dapat memanfaatkan sistem komunikasi ini selama pemadaman dan evakuasi selama keadaan darurat, pelatihan oleh instruktur profesional terhadap pengelola gedung dan penghuni, untuk bekerja sama dalam menghadapi keadaan darurat, program inspeksi reguler, pemeliharaan detektor dan sistem komunikasi yang semuanya terdokumentasi dengan baik.

\subsection{Visual Display}

Display adalah bagian dari lingkungan yang memberi informasi kepada pekerja agar tugastugasnya menjadi lancar (Sutalaksana, 2006). Display berfungsi sebagai "Sistem Komunikasi" yang menghubungkan fasilitas kerja maupun mesin kepada manusia (Nurmianto, 1996).

Menurut Bridger R.S. (1995) terdapat beberapa kelebihan dan kekurangan dalam penggunaan warna pada pembuatan display. Kelebihannya antara lain memberi tanda untuk data-data yang spesifik, informasi dapat lebih cepat diterima, dan dapat terlihat lebih natural. Sedangkan kekurangan dalam penggunaan warna pada pembuatan display diantaranya: dapat menyebabkan "fatique", membingungkan dan mungkin dapat memberikan reaksi yang salah, dan tidak bermanfaat bagi orang yang buta warna.

\section{Pembahasan}

\subsection{Kuesioner Pendahuluan}

Penelitian pendahuluan untuk mengetahui pentingnya sistem pencegahan dan penanggulangan bencana yang baik dilakukan dengan menyebarkan kuesioner. Berdasarkan kuesioner tersebut diperoleh hasil sebagai berikut:

Pertanyaan pertama dan kedua diberikan untuk mencari tahu profil pengguna Gedung X dari segi pekerjaan dan asal fakultas, sehingga dari hal tersebut dapat diketahui aktivitas, lama penggunaan, lokasi yang mungkin digunakan dari gedung ini sendiri. Berdasarkan hasil yang diperoleh pengguna terbesar adalah mahasiswa yaitu hampir 70\% dimana mereka juga merupakan pengguna dengan jangka waktu yang cukup lama karena memiliki banyak aktivitas di gedung ini seperti belajar di kelas, berkumpul di student center dan melakukan aktivitas lain di berbagai lokasi di gedung ini, dan masih banyak lagi. Selain itu terdapat juga karyawan non-dosen seperti pegawai administrasi, pegawai kerumahtanggaan, tenaga kebersihan serta tenant foodcourt. Maka dapat dilihat bahwa pengguna gedung ini sangat beragam dari segi usia, pekerjaan, kepentingan, dan waktu pemanfaatan gedung ini sendiri.

Pertanyaan berikutnya diajukan untuk mengetahui kondisi aktual dari gedung itu sendiri jika terjadi suatu kondisi bencana. Berdasarkan kemudahan pencarian terkait jalur darurat yaitu jalur evakuasi dan tempat berkumpul dapat terlihat bahwa sebagian responden mengatakan bahwa informasi tersebut masih kurang lengkap. Ketidaklengkapan tersebut diperkuat dari pertanyaan berikutnya yang memberikan hasil bahwa pengguna gedung masih merasa bahwa informasi terkait jalur evakuasi dan tempat berkumpul masih sulit dibaca dan ditemukan. Berdasarkan hal tersebut dapat diketahui bahwa visual management terkait hal tersebut masih sangat kurang. Padahal Gedung X merupakan gedung yang termasuk kategori high rise building yang tentu memiliki resiko yang cukup tinggi jika terjadi peristiwa bencana misalnya gempa bumi atau kebakaran.

Pertanyaan berikutnya yang ditanyakan pada responden berkaitan dengan perasaan kognitif yang dirasakan oleh responden dengan ketidaklengkapan dan ketidakjelasan jalur evakuasi dan tempat berkumpul dari Gedung X. Berdasarkan pertanyaan tersebut responden sebagian besar belum atau tidak merasa cemas atas kekurangan dan ketidaktahuan informasi yang seharusnya mereka miliki. Hal ini wajar terjadi karena kebutuhan akan hal tersebut belum ada sehingga perasaan membutuhkan juga belum ada. Kebutuhan akan adanya jalur evakuasi dan tempat berkumpul akan muncul jika terjadi bencana, tetapi sebenarnya hal tersebut juga akan sangat berbahaya karena saat terjadi bencana pasti seseorang cenderung untuk merasa takut, cemas, dan panik sehingga akan 
merasa kebingungan. Tidak dimilikinya informasi terkait bagaimana menghadapi hal tersebut tentu akan memberikan dampak yang lebih buruk.

\subsection{Pengumpulan Data Kualitatif}

Pengumpulan data kualitatif adalah data sekunder berupa jurnal, penelitian serta berbagai peraturan terkait gedung serta sistem pencegahan dan penanggulangan bencana yang ada. Penelitian terkait pencegahan dan penanggulangan bencana kebakaran dilakukan pada berbagai objek antara lain gedung rumah sakit (Hesna, dkk, 2009), gedung perkuliahan (Widowati, dkk, 2017; Suyono, dkk, 2011), dan hotel (Sujatmiko, 2016), dimana pada penelitian-penelitian tersebut memperhatikan kebutuhan bangunan terhadap adanya sistem evakuasi kebakaran dan berbagai sarana prasarana pencegahan dan penanggulangan yang berpatokan pada berbagai peraturan dan ketentuan yang ada.

Selain itu terdapat penelitian yang berfokus pada bagaimana petugas yang terlibat dalam aktivitas kesehatan dan keselamatan kerja di gedung tinggi dengan mengukur dan mengendalikan resiko yang terjadi (Yuliani, 2017). Selain itu, terdapat pula penelitian tentang pencarian faktor-faktor dari Service Quality yang menurut persepsi konsumen penting dan perlu diperbaiki dengan menggunakan Importance Performance Analysis. Pengembangan variabel Service Quality dilakukan dengan melihat kualitas dari layanan bagian manajemen keselamatan dan kesehatan kerja pada 3 gedung tinggi di Jakarta (Adi, 2009).

Dalam manajemen keselamatan dan kesehatan pada gedung tinggi (bangunan yang memiliki tinggi diatas 75 feet ( 25 meter), terdapat 3 kelompok yang memiliki kepentingan, yaitu kelompok penghuni gedung, jika dalam kasus gedung ini adalah mahasiswa, dosen, karyawan administrasi, karyawan kerumahtanggan dan pengunjung, kemudian kelompok berikutnya adalah karyawan yang bertugas untuk melakukan perawatan dan perbaikan gedung, baik yang termasuk karyawan gedung atau kontraktor yang berasal luar perusahaan, dan terakhir adalah kelompok stakeholder (Shimshuni, 2002). Pada perencanaan sistem manajemen keselamatan dan kesehatan gedung diperhatikan juga kemungkinan tindakan tidak rasional penghuni ketika bencana terjadi (Adi, 2009).

Aktivitas pencegahan kebakaran atau ledakan meliputi aktivitas berikut: identifikasi bahaya kebakaran atau ledakan yang terintegrasi dalam safety inspection program, membuat prosedur keselamatan dalam menerima, menyimpan, menangani, dan menggunakan cairan dan gas bahan mudah terbakar, pembatasan merokok pada area yang non hazardous pada fasilitas gedung, personel dilatih mengenai bahaya kebakaran atau ledakan dan pencegahannya. Pelatihan diikuti oleh karyawan, penggunan gedung dan supplier dan implementasi program housekeeping untuk membatasi akumulasi dan material yang mudah terbakar dan mudah menyala (Pusat Laboratorium Mabes Polri, 2001).

Perbaikan berkelanjutan (continuous improvement) sistem manajemen keselamatan dan kesehatan kerja perlu dilakukan dengan melakukan pemeriksaan berkala, pendokumentasian hasil pemeriksaan dan pengelolaan resiko yang kritis. Senior manajer ataupun supervisor membicarakan bagaimana melakukan eliminasi atau mengurangi bahaya kerja. Supervisor dan tenaga kerja harus memahami peranannya dalam sistem dan keterlibatan mereka dalam setiap kegiatan kerja (OHSAS 18001:2007).

\subsection{Perancangan}

\subsubsection{Pengembangan Variabel Deliveries}

Dari hasil pengumpulan data disusunlah variabel deliveries yang akan digunakan untuk perancangan struktur organisasi proyek dan kajian prosedur dan tugas tanggung jawab masingmasing. Dari 21 temuan pengumpulan data, disusun deliveries untuk menentukan faktor-faktor yang perlu diperhatikan dalam membuat sistem Pencegahan dan Penanggulangan Bencana gedung bertingkat tinggi. 
Pengertian deliveries dalam penelitian ini adalah: bentuk fisik (bisa dilihat) yang harus ada dalam sistem Pencegahan dan Penanggulangan Bencana gedung bertingkat tinggi.

Tabel 1. Pengembangan Variabel Deliveries

\begin{tabular}{|c|c|c|}
\hline Tahapan & Proses & Deliveries \\
\hline Pencegahan bencana & $\begin{array}{l}\text { Standarisasi kerja } \\
\text { Aturan } \\
\text { Pendidikan dan pelatihan } \\
\text { Pengawasan } \\
\text { Penelitian teknis } \\
\text { Penelitian medis } \\
\text { Penelitian psikologis } \\
\text { Evaluasi } \\
\text { Asuransi } \\
\text { Housekeeping }\end{array}$ & $\begin{array}{l}\text { SOP pencegahan bencana } \\
\text { SOP pendidikan dan pelatihan } \\
\text { SO pengawasan prosedur } \\
\text { pencegahan bencana }\end{array}$ \\
\hline Perawatan Peralatan & $\begin{array}{l}\text { Inspeksi dan evaluasi peralatan dan } \\
\text { detektor } \\
\text { Pemeliharaan jalur evakuasi }\end{array}$ & $\begin{array}{l}\text { SO pengawasan prosedur } \\
\text { pencegahan bencana }\end{array}$ \\
\hline Pendeteksian dini & $\begin{array}{l}\text { Prosedur deteksi dini } \\
\text { Struktur organisasi deteksi dini } \\
\text { Penanganan dini }\end{array}$ & $\begin{array}{l}\text { SOP pencegahan bencana } \\
\text { SO pengawasan prosedur } \\
\text { pencegahan bencana }\end{array}$ \\
\hline Evakuasi & $\begin{array}{l}\text { Prosedur/kebijakan evakuasi } \\
\text { Pembuatan organisasi evakuasi } \\
\text { Pembuatan visual display tanda-tanda } \\
\text { penyelamatan gedung } \\
\text { Pembuatan prosedur evakuasi } \\
\text { disabilitas } \\
\text { Pembuatan jalur evakuasi } \\
\text { Pembuatan instalasi/pemberian alat } \\
\text { keamanan } \\
\text { Pembekalan alat komunikasi petugas } \\
\text { evakuasi } \\
\text { Pembuatan prosedur pelaporan } \\
\text { bencana } \\
\text { Pengadaan tim evakuasi lantai } \\
\text { Pembuatan prosedur tim evakuasi } \\
\text { Pembuatan emergency response } \\
\text { teams }\end{array}$ & $\begin{array}{l}\text { SOP prosedur evakuasi } \\
\text { SO Evakuasi } \\
\text { Visual Display } \\
\text { SOP tim evakuasi } \\
\text { SOP emergency response } \\
\text { teams }\end{array}$ \\
\hline
\end{tabular}

\subsubsection{Pembuatan Struktur Organisasi}

Dari hasil pengumpulan data disusunlah variabel deliveries yang akan digunakan untuk perancangan struktur organisasi proyek dan kajian prosedur dan tugas tanggung jawab masingmasing.

Hasil pengembangan variabel deliveries menunjukan perlunya dua bagian dalam struktur organisasi, yaitu:

1. SO pengawasan prosedur pencegahan bencana

2. SO evakuasi

Adapun struktur organisasi untuk pencegahan bencana merupakan struktur organisasi yang tetap, karena pencegahan bencana memerlukan proses yang terencana dan berkesinambungan, sedangkan prosedur evakuasi merupakan proses yang bersifat proyek yang struktur organisasinya disesuaikan dengan kondisi petugas pada saat bencana terjadi. 


\subsubsection{Struktur Organisasi Pengawasan Prosedur Pencegahan Bencana (P3B)}

Perancangan struktur organisasi Pengawasan Prosedur Pencegahan Bencana (P3B) dibagi ke dalam 3 tahap pengolahan data, yaitu: tahap pertama penyusunan work breakdown structure (WBS), tahap kedua penjadwalan tugas, dan tahap ketiga perancangan struktur organisasi.

\subsubsection{Work Breakdown Structure (WBS)}

Work breakdown structure (WBS) adalah pengembangan rincian pekerjaan yang dasarnya diambil dari variabel deliveries. Hasil pengembangan variabel deliveries pada tabel 1 kemudian dijadikan output yang harus dihasilkan oleh satuan Organisasi Pengawasan Prosedur Pencegahan Bencana (P3B). Output yang dihasilkan kemudian dijabarkan ke dalam pekerjaan yang harus dilakukan, yaitu WBS-nya. Hasil pengembangan WBS ini dapat dilihat pada tabel 2 Pengembangan WBS.

Tabel 2. Pengembangan WBS

\begin{tabular}{|c|c|c|}
\hline & Output harus dihasilkan & $W B S$ \\
\hline Pencegahan bencana & $\begin{array}{l}\text { Standarisasi kerja } \\
\text { Aturan } \\
\text { Pendidikan dan pelatihan } \\
\text { Pengawasan } \\
\text { Penelitian teknis } \\
\text { Penelitian medis } \\
\text { Penelitian psikologis } \\
\text { Evaluasi } \\
\text { Asuransi } \\
\text { Housekeeping }\end{array}$ & $\begin{array}{l}\text { Analisis resiko kerja } \\
\text { Pembuatan standarisasi kerja } \\
\text { Pembuatan aturan prosedur } \\
\text { kerja dan petunjuk } \\
\text { pelaksanaannya } \\
\text { Menjalin kerjasama dengan } \\
\text { LPPM untuk melakukan } \\
\text { penelitian yang berkaitan } \\
\text { dengan analisis resiko, } \\
\text { standari sasi kerja dan visual } \\
\text { display } \\
\text { Melakukan evaluasi perubahan } \\
\text { standar kerja secara berkala } \\
\text { Menginventarisasi aset } \\
\text { perusahaan } \\
\text { Melakukan pengendalian } \\
\text { keamanan aset } \\
\text { Mengasuransikan dan merawat } \\
\text { asuransi aset } \\
\text { Menghitung, membeli, dan } \\
\text { instalasi peralatan aset } \\
\text { Melakukan pemeliharaan aset } \\
\text { Melakukan pendidikan dan } \\
\text { pelatihan karyawan } \\
\text { Bekerjasama dengan pejabat } \\
\text { struktural memberi } \\
\text { pengarahan periodik } \\
\text { Bekerjasama dengan pejabat } \\
\text { struktural mensosialisasikan } \\
\text { jadwal pemeliharaan dan } \\
\text { memberikan peringatan dini } \\
\text { kepada karyawan mengenai } \\
\text { apa saja yang akan terjadi } \\
\text { dalam pemeliharaan aset. }\end{array}$ \\
\hline Perawatan Peralatan & $\begin{array}{l}\text { Inspeksi dan evaluasi } \\
\text { peralatan dan detektor } \\
\text { Pemeliharaan jalur evakuasi }\end{array}$ & $\begin{array}{l}\text { Menjadwalkan pemeliharaan } \\
\text { aset }\end{array}$ \\
\hline
\end{tabular}


Tabel 2. Pengembangan WBS (lanjutan)

\begin{tabular}{|c|c|c|}
\hline & Output harus dihasilkan & WBS \\
\hline Pendeteksian dini & $\begin{array}{l}\text { Prosedur deteksi dini } \\
\text { Struktur organisasi deteksi } \\
\text { dini } \\
\text { Penanganan dini }\end{array}$ & $\begin{array}{l}\text { Membuat prosedur } \\
\text { pendeteksian dini terhadap } \\
\text { bencana } \\
\text { Membuat prosedur } \\
\text { penanganan dini bencana }\end{array}$ \\
\hline Evakuasi & $\begin{array}{l}\text { Prosedur/kebijakan evakuasi } \\
\text { Organisasi evakuasi } \\
\text { Visual display tanda-tanda } \\
\text { penyelamatan gedung } \\
\text { Prosedur evakuasi disabilitas } \\
\text { Jalur evakuasi } \\
\text { Instalasi/pemberian alat } \\
\text { keamanan } \\
\text { Alat komunikasi petugas } \\
\text { evakuasi } \\
\text { Prosedur pelaporan bencana } \\
\text { Tim evakuasi lantai } \\
\text { Prosedur tim evakuasi } \\
\text { Emergency response teams }\end{array}$ & $\begin{array}{l}\text { Membuat prosedur dan } \\
\text { kebijakan evakuasi } \\
\text { Membuat dan merawat visual } \\
\text { display tanda-tanda } \\
\text { penyelamatan gedung } \\
\text { Melakukan pengawasan } \\
\text { pelaksanaan prosedur evakuasi } \\
\text { Mengevaluasi prosedur apakah } \\
\text { sudah baik atau perlu } \\
\text { perbaikan } \\
\text { Menghitung jumlah kebutuhan } \\
\text { dan membeli alat komunikasi } \\
\text { Membuat aturan dan prosedur } \\
\text { tim evakuasi } \\
\text { Menghitung dan membeli } \\
\text { perlengkapan tim evakuasi }\end{array}$ \\
\hline
\end{tabular}

\subsubsection{Penjadwalan tugas}

Proses penjadwalan tugas adalah tahap pengolahan data setelah mengembangkan WBS. Setiap WBS kemudian dianalisis dan dikelompokkan ke dalam kategori umumnya. Dari 23 WBS yang berhasil dikembangkan pada tabel 2, penelitian ini berhasil mengelompokkan ke dalam 3 kelompok WBS, yaitu kelompok penelitian dan pengembangan mitigasi bencana, kelompok pengadaan dan pemeliharaan mitigasi bencana, serta pendidikan, pelatihan, dan inspirasi karyawan.

Dari ke tiga kelompok yang telah dikembangkan maka disusunlah output yang dihasilkan, seperti tampak pada tabel 3 .

Tabel 3. Penjadwalan Tugas

\begin{tabular}{|l|l|l|}
\hline \multicolumn{1}{|c|}{ Kelompok WBS } & \multicolumn{1}{|c|}{ WBS } & \multicolumn{1}{|c|}{ Output harus dihasilkan } \\
\hline Penelitian dan & Analisis resiko kerja & Standarisasi kerja \\
Pengembangan mitigasi & Pembuatan standarisasi kerja & Aturan \\
& Pembuatan aturan prosedur kerja dan & Penelitian teknis \\
& petunjuk pelaksanaannya & Penelitian medis \\
& Menjalin kerjasama dengan LPPM & Penelitian psikologis \\
& untuk melakukan penelitian yang & Prosedur/kebijakan evakuasi \\
& berkaitan dengan analisis resiko, & Prosedur pelaporan bencana \\
& standarisasi kerja dan visual display & Organisasi evakuasi \\
& Melakukan evaluasi perubahan standar & Prosedur evakuasi disabilitas \\
& kerja secara berkala & Penyusunan tim evakuasi \\
& Membuat prosedur pendeteksian dini & lantai \\
& terhadap bencana & Prosedur tim evakuasi \\
& Membuat prosedur penanganan dini & Evaluasi \\
& bencana & \\
\hline
\end{tabular}


Tabel 3. Penjadwalan Tugas (lanjutan)

\begin{tabular}{|c|c|c|}
\hline Kelompok WBS & $W B S$ & Output harus dihasilkan \\
\hline & $\begin{array}{l}\text { Membuat prosedur dan kebijakan } \\
\text { evakuasi } \\
\text { Mengevaluasi prosedur apakah sudah } \\
\text { baik atau perlu perbaikan } \\
\text { Membuat aturan dan prosedur tim } \\
\text { evakuasi }\end{array}$ & \\
\hline $\begin{array}{l}\text { Pengadaan dan } \\
\text { pemeliharaan mitigasi } \\
\text { bencana }\end{array}$ & $\begin{array}{l}\text { Menginventarisasi aset perusahaan } \\
\text { Melakukan pengendalian keamanan } \\
\text { aset } \\
\text { Mengasuransikan dan merawat } \\
\text { asuransi aset } \\
\text { Menghitung, membeli, dan instalasi } \\
\text { peralatan aset } \\
\text { Melakukan pemeliharaan aset } \\
\text { Menjadwalkan pemeliharaan aset } \\
\text { Membuat dan merawat visual display } \\
\text { tanda-tanda penyelamatan gedung } \\
\text { Menghitung jumlah kebutuhan dan } \\
\text { membeli alat komunikasi } \\
\text { Menghitung dan membeli } \\
\text { perlengkapan tim evakuasi }\end{array}$ & $\begin{array}{l}\text { Inspeksi dan evaluasi } \\
\text { peralatan dan detektor } \\
\text { Pemeliharaan jalur evakuasi } \\
\text { Visual display tanda-tanda } \\
\text { penyelamatan gedung } \\
\text { Jalur evakuasi } \\
\text { Instalasi/pemberian alat } \\
\text { keamanan } \\
\text { Alat komunikasi petugas } \\
\text { evakuasi } \\
\text { Evaluasi } \\
\text { Asuransi } \\
\text { Housekeeping }\end{array}$ \\
\hline $\begin{array}{l}\text { Pendidikan, Pelatihan, } \\
\text { Inspirasi karyawan }\end{array}$ & $\begin{array}{l}\text { Melakukan pendidikan dan pelatihan } \\
\text { karyawan } \\
\text { Bekerjasama dengan pejabat struktural } \\
\text { memberi pengarahan periodik } \\
\text { Bekerjasama dengan pejabat struktural } \\
\text { mensosialisasikan jadwal } \\
\text { pemeliharaan dan memberikan } \\
\text { peringatan dini kepada karyawan } \\
\text { mengenai apa saja yang akan terjadi } \\
\text { dalam pemeliharaan aset. } \\
\text { Melakukan pengawasan pelaksanaan } \\
\text { prosedur evakuasi }\end{array}$ & $\begin{array}{l}\text { Pendidikan dan pelatihan } \\
\text { Pengawasan pelaksanaan } \\
\text { Evaluasi }\end{array}$ \\
\hline
\end{tabular}

\subsubsection{Hasil Struktur Organisasi}

Berdasarkan pembuatan work breakdown structure dan penugasan di atas maka dapat disimpulkan bahwa diperlukan 3 fungsi dalam Struktur Organisasi Pengawasan Prosedur Pencegahan Bencana (P3B). Adapun ketiga fungsi tersebut adalah sebagai berikut:

1. Penelitian dan pengembangan mitigasi bencana

2. Pengadaan dan pemeliharaan mitigasi bencana

3. Pendidikan, pelatihan, inspirasi karyawan

Perancangan struktur organisasi yang digunakan menggunakan struktur organisasi fungsional. Jika dilihat dari 3 fungsi di atas, maka diperoleh struktur organisasinya seperti tampak pada Gambar 4.1 Usulan Struktur Organisasi Pengawasan Prosedur Pencegahan Bencana (P3B), yaitu sebagai berikut: 


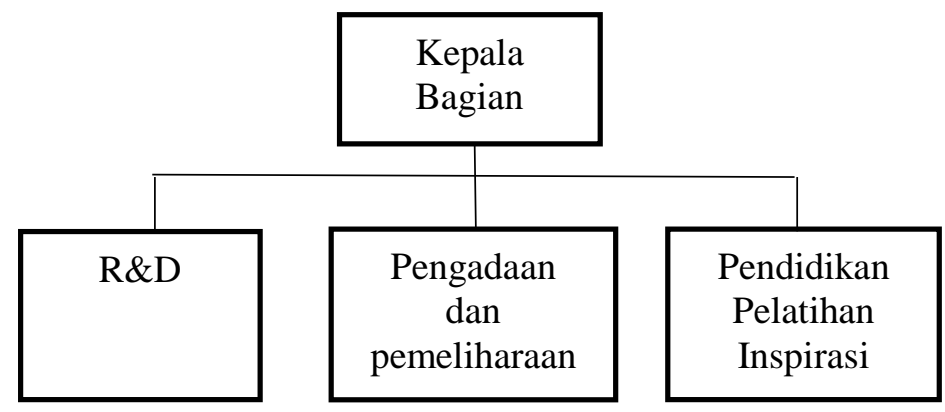

Gambar 1. Usulan Struktur Organisasi Pengawasan Prosedur Pencegahan Bencana (P3B)

\subsubsection{Struktur Organisasi Evakuasi}

Struktur Organisasi Evakuasi ini bersifat proyek, sehingga bentuk struktur organisasi yang sesuai adalah struktur organisasi matriks. Karena adanya keterbatasan waktu dalam penelitian, struktur organisasi ini tidak dibahas dalam penelitian ini. Dalam perancangan struktur organisasi Pengawasan Prosedur Pencegahan Bencana (P3B) telah dibahas bahwa tugas bagian R\&D adalah membuat satuan tim dan dalam pembuatannya bisa dilakukan perancangan struktur organisasi evakuasi.

\subsubsection{Perancangan Visual Display}

Selain perancangan secara manajerial, dilakukan juga perancangan sarana dan prasana untuk dapat meningkatkan keselamatan pengguna gedung saat terjadinya bencana. Perancangan yang dilakukan adalah perancangan display informasi untuk memudahkan mengarahkan pengguna gedung mencari jalur evakuasi saat terjadi bencana. Display yang baik harus mudah untuk dideteksi keberadaaanya, mudah dikenali atau mudah dibaca, dan mudah untuk dipahami isinya (Nurmianto, 2008). Untuk mengklasifikasikan kegiatan yang terjadi di dalam gedung, penelitian akan menggunakan kategori signage oleh Gibson (2009). Signage dibagi menjadi beberapa kategori, yaitu:

- Identification Sign

Perancangan identification sign yang diakukan pada gedung ini adalah berupa penanda yang diberikan pada setiap lantai pada tangga darurat agar mudah mengindentifikasi keberadaan lantai yang sedang dilewati saat sedang melakukan evakuasi melalui pintu darurat.

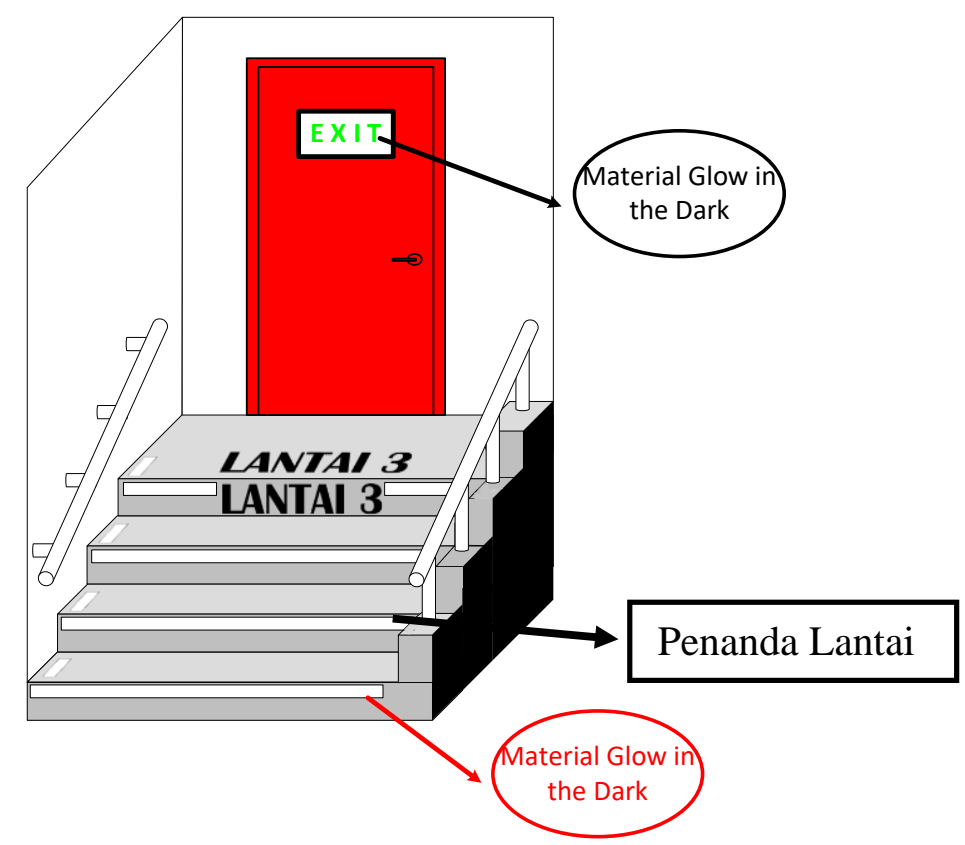

Gambar 2. Hasil Penempatan Penanda Lantai Pada Tangga Darurat 
- Directional Sign

Directional sign yang disarankan digunakan sebagai penunjuk arah ke pintu-pintu keluar atau mengarahkan pada titik kumpul. Penunjuk arah ini diletakkan di tempat-tempat strategis yang mudah dilihat oleh pengguna gedung.

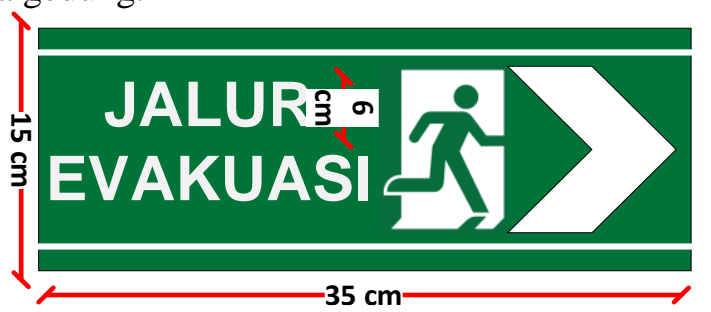

Gambar 3. Penunjuk Arah Jalur Evakuasi Berdasarkan ANSI Z535

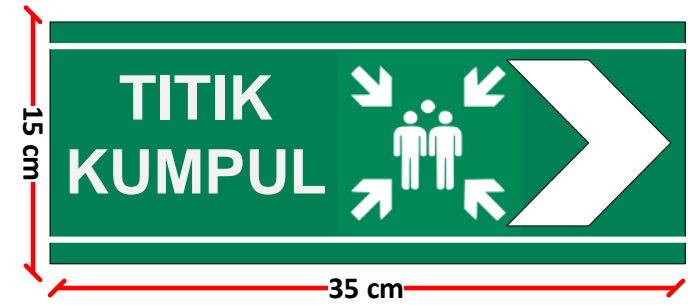

Gambar 4. Penunjuk Arah Titik Kumpul Berdasarkan ANSI Z535

- Orientation Signs/Operational \& Directory Sign

Penempatan sign dan informasi lain yang dibutuhkan, dikompilasi pada sebuah denah seperti yang terlihat pada Gambar 5. Denah ini dapat digunakan untuk memberikan informasi pada pengguna gedung tentang letak dan arah ruangan, fasilitas yang tersedia pada lantai tersebut, dan berbagai informasi lainnya.

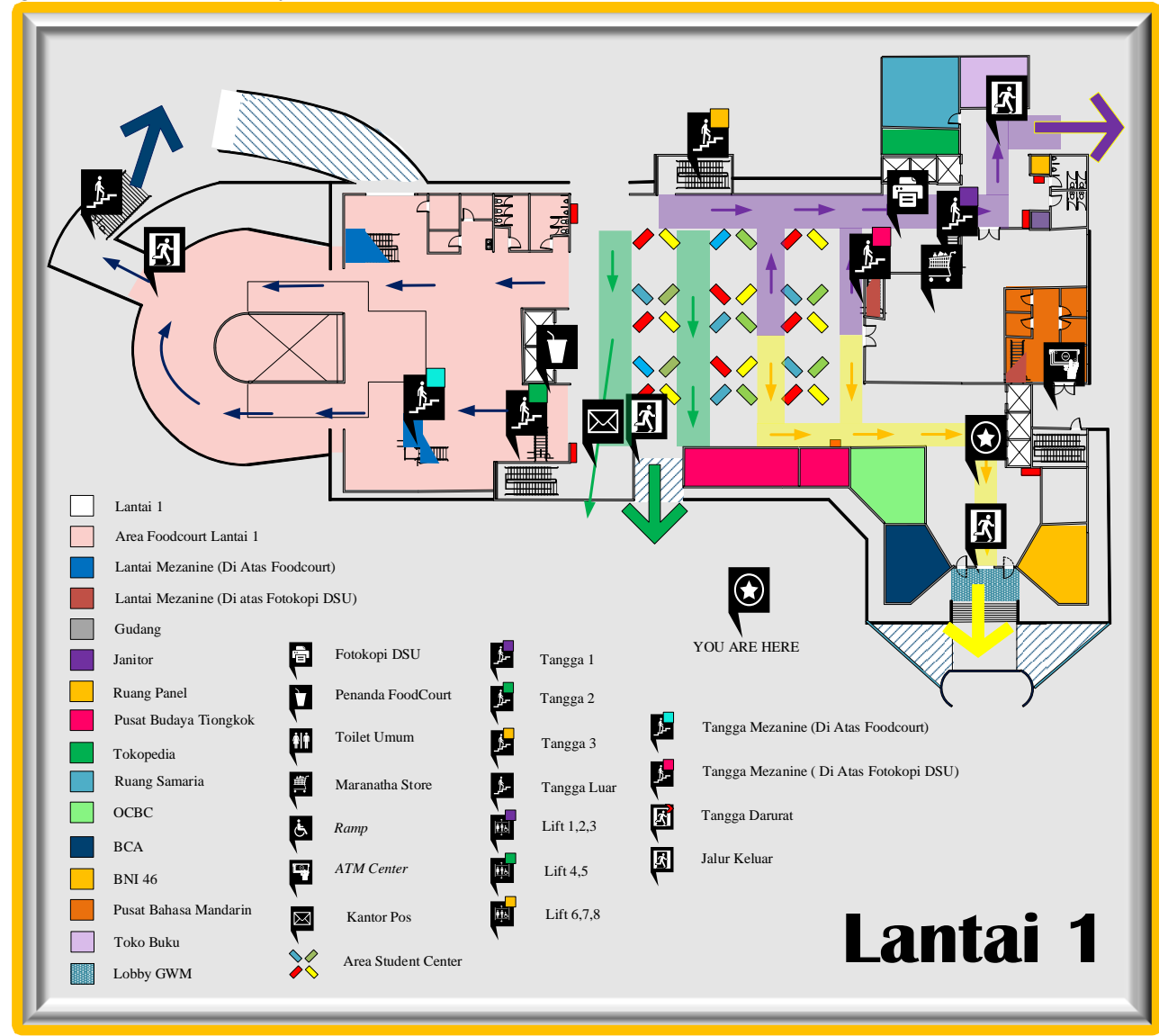

Gambar 5. Hasil Penggambaran Denah Lantai 
- Regulatory Sign/Safety Signs

Kategori sign terakhir adalah penanda yang digunakan untuk memberikan tanda lokasi APAR sehingga saat terjadi bencana kebakaran, dapat segera ditanggulangi sebelum api semakin membesar.

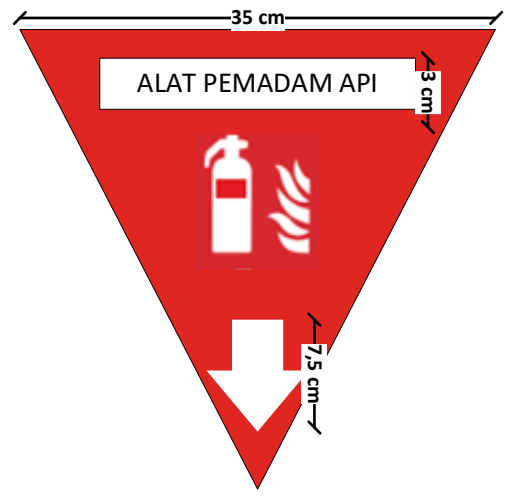

Gambar 6. Penanda Lokasi APAR Berdasarkan ANSI Z535

Perancangan signage tersebut menggunakan standar American National Standards Institute (ANSI) Z535 untuk ukuran dan dimensinya.

\section{Kesimpulan dan Saran}

\subsection{Kesimpulan}

Berdasarkan pengumpulan data kualitatif yang diperoleh, terdapat beberapa hal yang harus diperhatikan antara lain bencana yang dapat terjadi pada gedung tinggi, prosedur pencegahan dan penanggulangan yang harus ada, stakeholder atau pihak yang perlu dilibatkan, dan sarana prasarana apa yang perlu disiapkan. Berdasarkan hal tersebut maka dilakukan perancangan struktur organisasi Pengawasan Prosedur Pencegahan Bencana (P3B) yang dibagi ke dalam 3 tahap pengolahan data, yaitu Tahap 1: Penyusunan work breakdown structure (WBS), Tahap 2: Penjadwalan tugas, dan Tahap 3: Perancangan struktur organisasi. Tahapan perancangan tersebut pada akhirnya akan menghasilkan hal-hal apa saja yang perlu dipersiapkan dalam menghadapi bencana, mulai dari SOP apa saja yang dibutuhkan, SO yang terbentuk untuk dikembangkan lebih lanjut, dan terakhir adalah rancangan visual display yang dibutuhkan.

\subsection{Saran}

Saran untuk penelitian selanjutnya adalah melakukan penerapan pada rancangan P3B yang dibuat dan melakukan evaluasi terhadap hal tersebut. Selain itu, dapat dilakukan perancangan sarana dan prasarana lain yang mendukung lancarnya penerapan P3B yang ada.

\section{Daftar Pustaka}

Adi, Yoyok H Prasetyo (2019), Sistem Manajemen Keselamatan dan Kesehatan Kerja pada Bangunan Bertingkat Tinggi, Tesis Program Pascasarjana Universitas Terbuka.

American National Standards Institute (ANSI) Z535.

Ching, F. DK. (1987), Interior Design Illustrated. New York: Von Nostrand Reinhold Company.

Gibson, David (2009), The Wayfinding Handbook Information Design for Public Space, New York: Princeton Architectural Press

Hardiyansyah, Haris (2013), Wawancara, Observasi, dan Focus Groups, Rajawali Pers. 
Hesna, Yervi, Benny Hidayat dan Satria Suwanda (2009), Evaluasi Penerapan Sistem Keselamatan Kebakaran Pada Bangunan Gedung Rumah Sakit DR. M. Djamil Padang, Jurnal Rekayasa Sipil Vol. 5 No.2, 65-76.

Larson, Erick W. and Gray, Clifford F. (2011), Project Management: The Managerial Process, $5^{\text {th }}$ edition, McGraw Hill International.

Nurmianto, Eko (2008), Ergonomi Konsep Dasar dan Aplikasiya, Edisi Kedua, Surabaya: Guna Widya.

OHSAS 18001:2007 and OHSAS 18002:2008, The Occupational Health and Safety Management System, Binary Ltd. United Kingdom.

Olishifski, J.B. (1985), Fundamentals of Industrial Hygiene, National Safety Council, Chicago.

Pusat Laboratorium Forensik Mabes Polri (2001), Kasus Kebakaran 1990-2001 di Tempat Kerja dan Bukan Tempat Kerja, Jakarta, Mabes Polri.

Shimshuni, Y. (2002), Permasalahan Gedung Tinggi, California: USA

Sujatmiko, Wahyu (2016), Penerapan Standar Keselamatan Evakuasi Kebakaran Pada Bangunan Gedung Di Indonesia, Jurnal Permukiman, Vol. 11 No.2, 116-127

Suma'mur (1986), Keselamatan Kerja dan Pencegahan Kecelakaan. Depnaker, Surabaya.

Sutalaksana (2006), Tata Cara Kerja. Lab Ergonomi Institut Teknologi Bandung. Bandung. Widowati, Evi, et. al. (2017), Analisis Keselamatan Gedung Baru F5 Universitas Negeri Semarang sebagai Upaya Tanggap terhadap Keadaan Darurat, Unnes Journal of Public Health, Vol. 6 No.2, 101-106.

Suyono, Annisa Maharani dan Oktri Mohammad Firdaus (2011), Evaluasi Jalur Evakuasi pada Gedung Bertingkat 7 (Tujuh) Lantai (Studi Kasus Di Gedung Graha Universitas Widyatama Bandung), Proceeding 1st National Conference of Indonesian Ergonomics Society 2011, 1-247 - 1254.

Yuliani, Upit (2017), Manajemen Risiko Keselamatan dan Kesehatan Kerja (K3) pada Infrastruktur Gedung Bertingkat, Jurnal Desain Konstruksi, Vol. 16 No.1, 92-100. 